\title{
O Império do Brasil e a política de intervenção no Rio da Prata (1843-1865)
}

Salvador Lima

Università degli Studi di Bologna, Italia

Maestrando en Relaciones Internacionales

Europa-América Latina

salvador.lima.89@gmail.com

César de Oliveira Lima Barrio, O Império do Brasil e a política de intervenção no Rio da Prata (1843-1865), Brasilia, Fundação Getulio Vargas, 2018, 496 pp., ISBN 978-85-7631-792-0

En el marco de las recientes innovaciones en historia de las relaciones internacionales en Brasil, César de Oliveira Lima Barrio expone en O Império do Brasil e a política de Intervenção no Rio da Prata (1843-1865) todo su conocimiento sobre la teoría de las relaciones internacionales, para explicar el intervencionismo brasileño en las repúblicas del Río de la Plata en las décadas centrales de la historia imperial. Considerando a la política exterior platina como uno de sus ejes históricos, Barrio explica el intervencionismo como una etapa hobbesiana en sí misma, diferenciada del momento anterior de neutralidad de las Regencias y de la fase siguiente de dualismo realista-moral del barón de Río Branco y, para encontrar sus explicaciones, apela a la concepción ideacional de la diplomacia y de la guerra de Pierre Renouvin y al juego de los dos niveles entre la política doméstica e internacional de Robert Putnam. La hipótesis del autor es que la etapa intervencionista habría sido una síntesis entre la dimensión externa del ideario del Partido Conservador dominante en la Corte y unas "fuerzas profundas" de naturaleza axiológica, arraigadas en la longue durée, que habrían condicionado las relaciones internacionales del subsistema platino desde los tiempos coloniales y hasta la Guerra

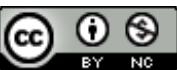

4.0 Internacional

Secuencia. Reseñas, 2021

http://secuencia.mora.edu.mx
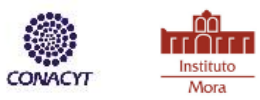
del Paraguay. Como el propio autor lo dice, su tesis de índole idealista no pretende desbancar los trabajos previos de sus colegas, que han explicado el activismo militar y diplomático brasileño en el Plata a través de cuestiones estructurales de la sociedad y la economía regional, así como por motivos de inestabilidad política o formación estatal. Barrio condensa estas tesis y, como analista de relaciones internacionales, no adopta un enfoque exclusivamente realista o idealista. Originalmente, el autor sostiene que la realpolitik brasileña de las décadas centrales del siglo XIX estuvo fundamentada en motivos ideacionales, morales e históricos que sirvieron como armazón espiritual para la política del poder del Partido Conservador, en el ámbito doméstico y el internacional, a la vez.

En el primer capítulo, "O Império do Brasil e o Rio da Prata”, Barrio explora los elementos estructurales del tiempo largo, las "fuerzas profundas" que habrían moldeado la realidad social, económica y política del Brasil y el Río de la Plata. Como otros autores, entiende que el conflicto bipolar entre el Brasil y la Argentina en el siglo XIX es tributario de las disputas coloniales entre España y Portugal por las fronteras mal definidas entre sus territorios americanos. Tras las independencias, la Plata y el Brasil formaron el subsistema platino de relaciones internacionales, el cual incorporaría dos estados-tapón que buscarían mantener su independencia mediante el péndulo entre la Argentina y Brasil, en el caso uruguayo, y el aislamiento, en el caso paraguayo. Siguiendo la tradición brasileña, el autor asume que los gobiernos de Buenos Aires buscaban la reconstrucción del territorio virreinal, junto con el control de la navegación de los ríos anteriores, exacerbando así unos conflictos facciosos que cruzaban las líneas estatales recíprocamente. En cuanto al Brasil, Barrio describe la política exterior platina de las Regencias (1831-1840) como una fase de neutralidad, hasta 1843, cuando el Imperio buscó la alianza con Juan Manuel de Rosas para aplacar a la revolución republicana en Río Grande do Sul.

El segundo capítulo, "Gênese: intervencionismo civilizador", inicia con la idea de que el rechazo de Rosas a la invitación de alianza y su aparente aspiración de recrear el virreinato en una "Gran Argentina" coincidieron con el encumbramiento en la Corte imperial del Partido Conservador. Barrio explica con amplitud el juego de dos niveles de la política saquarema, desarrollando la dialéctica de inspiración 
conservadora entre orden y libertad. La tesis del autor es que, mientras que, en el plano doméstico, los conservadores concretaban el regresso o la reversión de las reformas liberales de las Regencias y afirmaban la autoridad central de la monarquía de Pedro II, en el ámbito externo encontraron en la guerra contra Rosas una causa y un discurso que encumbraba el rol civilizador del Imperio frente a la barbarie del Río de la Plata. De este modo, al tiempo que la abolición del tráfico de esclavos y la ley de tierras legitimaban el discurso iluminista del Imperio, el intervencionismo en Uruguay fue el modo de los saquaremas en el gobierno de consolidar la autoridad del Estado monárquico y legitimar su poder hacia adentro y hacia afuera.

La caída de Rosas abre la etapa del predominio brasileña en el subsistema platino y de los gabinetes de Conciliación en la política imperial. En el tercer capítulo, "Evolução: intervencionismo pragmático", Barrio desarrolla la etapa más hobbesiana y realista del ejercicio de poder brasileño en el Río de la Plata. De acuerdo con el juego de los dos niveles que plantea el autor, la primacía del Imperio en el subsistema platino, entre 1852 y 1859, era la dimensión externa de la primacía del Partido Conservador en el sistema de Conciliación partidaria que dominó al gabinete de ministros y al Parlamento. Victoriosos adentro y afuera, los saquaremas habrían conducido al Imperio a una etapa de estabilidad política y crecimiento económico, liderando la Conciliación entre orden y libertad y consolidando la identidad nacional mediante una política exterior firme. Barrio afirma que estos tiempos fueron los de la verdadera realpolitik y los de un intervencionismo pragmático. Según el autor, guiado por el cálculo racional de interés, Brasil tenía la autoridad y el poder material suficientes para intervenir en el Río de la Plata y defender sus intereses económicos, territoriales y políticos.

En el último capítulo, "Crise: intervencionismo relutante", hacia fines de la década de 1850, con la muerte del marqués de Paraná y las victoriales electorales para los liberales, la lógica saquarema del poder y la política de la intervención entran en crisis. Barrio afirma que el reacomodamiento de las fuerzas internas significó también una mirada crítica sobre la política platina de la intervención. A pesar de la reunificación argentina, las alianzas facciosas del Río de la Plata mantuvieron su carácter transnacional, desestabilizando las relaciones del E-ISSN 2395-8464 https://doi.org/10.18234/secuencia.v0i0.1924 
subsistema platino, mientras que un gabinete brasileño dominado por los liberales se rehusaba a intervenir en el Plata y se acercaba al gobierno de Bartolomé Mitre. De acuerdo con Barrio, las disputas partidarias del gabinete y del Parlamento limitaron la capacidad de acción del Imperio en la región, en momentos en que la nueva guerra civil uruguaya preparaba una crisis en la región. Articulando los asuntos domésticos con los internacionales, Barrio explica que las tensiones con el gobierno de Montevideo (apoyado por Paraguay y Entre Ríos) y los daños ocasionados en la frontera a propiedades de ciudadanos brasileños fueron la pólvora que eligieron los conservadores para deslegitimar el intervencionismo reluctante de los liberales y empujarlos a las demostraciones de fuerza en Uruguay. Tras la intervención diplomática del Brasil en Montevideo y la posición amenazante del Ejército Imperial, el ataque de Francisco Solano López al buque Marqués de Olinda y al Mato Grosso llevó al Brasil a la guerra declarada, dando lugar a la formación de un gabinete de halcones. Desde 1864 y hasta 1870, tiene lugar una nueva etapa de intervencionismo belicista y exaltado, que hallaría en la Guerra de la Triple Alianza una verdadera causa nacional y una nueva lucha contra la barbarie de otro caudillo platino.

En conclusión, mediante un enfoque ideacional y considerando el juego político de los dos niveles, Barrio afirma el poder de las "fuerzas profundas" de la historia y del ideario monárquico-conservador para determinar la orientación intervencionista de la política brasileña en el Río de la Plata, durante las décadas de predominio saquarema. De este modo, O Império do Brasil e a política de Intervenção no Rio da Prata (1843-1865) pretende llenar un vació en los estudios del pensamiento político brasileño y manifiesta la convicción del autor de que, aún en el marco realista de la política del poder, las ideas importan y pueden conducir las acciones internas y externas de los Estados. 